\title{
Análise do comportamento de conexão vertical de painéis estruturais cerâmicos pré-fabricados
}

\author{
Analysis of the behavior of vertical connections of \\ prefabricated structural ceramic panels
}

\section{Reginaldo de Matos Manzano \\ Humberto Ramos Roman \\ Luis Alberto Gómez}

Reginaldo de Matos Manzano Departamento de Engenharia Civil, Centro Tecnológico Universidade Federal de Santa Rua João Pio Duarte Silvatirina Córrego Grande Florianópolis - SC - Brasi CEP 88040-900

Tel.: (48) 3721-7687

E-mail:

reginaldo.manzano@gmail.com

Humberto Ramos Roman Departamento de Engenharia Civil, Centro Tecnológico

Universidade Federal de Santa Catarina

Tel.: (48) 3721-2394

E-mail: humberto.roman@ufsc.br

Luis Alberto Gómez Departamento de Engenharia Civil, Centro Tecnológico Universidade Federal de Santa Tel : (48) $331-$ Catarina E-mail: luis.gomez@ufsc.br

Recebido em 16/11/12 Aceito em 03/02/13

\section{Resumo}

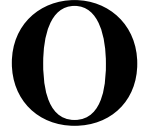

presente trabalho visa avaliar a influência do modelo de ligação no desempenho estrutural de painéis pré-fabricados de alvenaria. De modo geral, a conexão entre os painéis estruturais cerâmicos préfabricados apresentam comportamento idêntico ao da amarração indireta da alvenaria estrutural. Este fato aliado à falta de dados suficientes para o estabelecimento de parâmetros que possibilitem a consideração da interação entre os painéis induz ao dimensionamento das edificações pré-fabricadas em alvenaria estrutural pelo "Método das paredes isoladas". Entretanto, os resultados obtidos por meio de ensaios experimentais e através de análise numérica demonstraram que a generalização pode levar ao erro, uma vez que para o modelo de conexão avaliado houve a presença da interação entre o painel central e os da extremidade.

Palavras-chave:. Pré-fabricação. Alvenaria. Conexão. Interação.

\section{Abstract}

This paper aims to evaluate the influence of the connection model on the structural performance of prefabricated masonry panels. In general, the connections between prefabricated structural ceramic panels have a similar behavior to that of indirect connections of masonry structures. This fact, associated with a lack of sufficient data to establish parameters that allow the consideration of the interaction between the panels, has led to the use of the "Isolated Wall Method" in designing prefabricated, structural masonry buildings. However, the results obtained from experimental tests and numerical analysis indicated that generalization could lead to errors, since the evaluated connection model had interactions between the central panel and the end panels.

Keywords: Prefabricated. Masonry. Connection. Interaction. 


\section{Introdução}

Nas últimas décadas, observou-se uma busca contínua pelo aprimoramento tecnológico de processos e sistemas construtivos. Essa evolução teve início com a adoção do conceito de racionalização, o qual propiciou maior controle da qualidade, dos custos e do tempo de execução da edificação. Posteriormente, houve a introdução dos conceitos de pré-moldagem, pré-fabricação e industrialização. No caso da alvenaria, o uso desses conceitos resultou no desenvolvimento de processos construtivos baseados em painéis préfabricados. O emprego desses processos apresenta vantagens similares à adoção da racionalização, ou seja, aumento da velocidade de construção, maior economia, maior produtividade e melhor controle de qualidade, além da redução no desperdício de material. Entretanto, o desempenho dos painéis cerâmicos estruturais pré-fabricados depende de diversos fatores, entre os quais se destacam o modelo e o comportamento das conexões horizontal e vertical. O modelo da conexão adotada pode determinar como um painel irá se comportar na presença de forças de compressão, flexão e cisalhamento. No caso das conexões verticais, objeto de estudo desta pesquisa, a principal função, segundo Schultz (1994), consiste em transmitir para as estruturas verticais as tensões ocasionadas pela presença de forças horizontais, sejam elas provenientes de um evento acidental, de sismos ou do próprio vento.

No processo construtivo em alvenaria estrutural a junção entre as paredes adjacentes pode ocorrer de duas formas distintas. A primeira consiste na amarração direta ou contrafiada, e a segunda, na amarração indireta. A forma como acontece essa junção altera significativamente o comportamento da edificação como um todo, fato este que tem sido analisado em diversas pesquisas realizadas nas últimas décadas, entre as quais se destacam as desenvolvidas por Lissel, Shrive e Page (2000), Camacho et al. (2001), Peleteiro (2002), Silva (2003), Corrêa (2003) e Capuzzo Neto (2000, 2005). De acordo com essas pesquisas relacionadas, nas paredes adjacentes cuja união ocorre por amarração direta ou contrafiada há a presença da interação entre elas, ou seja, há a distribuição e a homogeneização tanto das tensões verticais quanto das tensões horizontais ao longo de suas alturas. Em outras palavras, a presença da interação induz a uma ampliação da capacidade de carga das paredes. Nas paredes unidas por amarração indireta, procedimento similar ao praticado em processos pré-fabricados em alvenaria cerâmica, a interação ainda ocorre, porém sua intensidade tende a variar com a rigidez e o modelo da conexão. Isso, aliado à ausência de dados sobre a eficiência desse tipo de amarração, segundo Capuzzo Neto (2005), dificulta o estabelecimento de parâmetros que viabilizem sua consideração na etapa de projeto. Apesar da relevância do estudo das conexões dos painéis estruturais cerâmicos pré-fabricados, para garantir a estabilidade estrutural da edificação, constatou-se a existência de uma lacuna de conhecimento devido à ausência de pesquisas que abordem esse tema.

Diante disso, visando contribuir para o aprimoramento dos processos construtivos em alvenaria estrutural, buscou-se no presente estudo analisar o comportamento de um modelo de conexão vertical concebido para atuar em conjunto com os painéis estruturais cerâmicos préfabricados na execução de edificações com até cinco pavimentos.

\section{Metodologia}

A investigação do comportamento do modelo de conexão abordado seguiu as etapas a seguir.

A primeira etapa consistiu na determinação das propriedades físicas relevantes de cada material e componente utilizado na confecção da conexão avaliada para subsidiar a análise dos dados experimentais e a construção do modelo numérico. Nessa etapa também foram determinadas as resistências de aderência à tração na flexão e à compressão de prismas de unidades cerâmicas estruturais, com o intuito de verificar o comportamento do conjunto unidade cerâmicaargamassa.

A segunda etapa foi referente ao ensaio experimental do corpo de prova com seção transversal em "H" (Figura 3). Porém, devido à complexidade inerente a esse tipo de corpo de prova, foram confeccionadas apenas três unidades com uma única configuração de conexão vertical. Os dados obtidos nessa etapa auxiliaram a compreender seu comportamento e a calibrar o modelo numérico.

Finalizada a etapa anterior, deu-se início à terceira, ou seja, a definição do modelo numérico da configuração abordada durante $\mathrm{o}$ ensaio experimental. Este modelo, depois de calibrado, serviu de base para a elaboração de três versões distintas:

(a) modelo numérico no qual foram adotados os tipos de apoios e propriedades dos materiais empregados no ensaio experimental, ou seja, na composição da armadura, utilizou-se o aço CA-50; 
(b) modelo numérico semelhante ao anterior, entretanto, com a alteração do tipo de aço da armadura para CA-25; e

(c) modelo numérico semelhante ao primeiro caso, entretanto, com a alteração dos apoios para toda a base do prisma.

A variação proposta no caso do segundo modelo numérico teve por princípio auxiliar na identificação do nível de influência das propriedades do aço no comportamento do conjunto painéis-conexões. No terceiro modelo numérico, a alteração na forma dos apoios visou propiciar a investigação da presença das forças de interação entre os painéis estruturais préfabricados cerâmicos, ou seja, a distribuição da carga aplicada entre o painel central e os painéis da extremidade componentes do corpo de prova com seção transversal em " $H$ ".

\section{Caracterização dos materiais e componentes utilizados}

A opção pelo uso de componentes em escala natural na verificação do desempenho das conexões verticais dos painéis teve por base as pesquisas desenvolvidas por Camacho et al. (2001), Silva (2003) e Capuzzo Neto (2005). De acordo com esses autores, o uso da escala reduzida na avaliação da amarração indireta da alvenaria produz resultados divergentes aos das análises executadas em escala 1:1.

A caracterização do agregado miúdo consistiu na realização de ensaios embasados em procedimentos prescritos pelas normas brasileiras (NBR 6467 (ABNT, 2006), NBR 7211 (ABNT, 2009), NBR 7221 (ABNT, 1987), NBR 7251 (ABNT, 1982) e NBR 13600 (ABNT, 1999)) e do Mercosul (ABNT NM 26 (ASOCIACIÓN..., 2009a), ABNT NM 27 (ASOCIACIÓN..., 2001a), ABNT NM 46 (ASOCIACIÓN..., 2003a), ABNT NM 49 (ASOCIACIÓN..., 2001b), ABNT NM 52 (ASOCIACIÓN..., 2009b) e ABNT NM 248 (ASOCIACIÓN..., 2003b)). Os ensaios executados abordaram a granulometria, o coeficiente de inchamento, o índice de materiais pulverulentos e das impurezas orgânicas, a massa específica e a massa unitária.

A caracterização da argamassa de assentamento/grauteamento teve os procedimentos de ensaio norteados pelas recomendações das normas brasileiras (NBR 8522 (ABNT, 2003), NBR 13276 (ABNT, 2002), NBR 13277 (ABNT, 1995), NBR 13278 (ABNT, 2005a), NBR 13279 (ABNT, 2005b) e NBR 13281 (ABNT, 2001)). Nesses ensaios visou-se à determinação do índice de consistência, do teor de ar incorporado, da densidade, do índice de retenção de água, da resistência à compressão e à flexão, e do módulo de elasticidade.

A caracterização da unidade cerâmica estrutural ocorreu com base nos requisitos e parâmetros previstos na norma brasileira NBR 15270-1 (ABNT, 2005c). Os ensaios tiveram por objetivo a determinação das variações geométricas, da resistência à compressão, do índice de absorção de água, do índice de absorção de água inicial, da massa seca, da massa úmida e da área líquida. Entretanto, para a concepção do modelo numérico foi necessária a adoção de mais dois dados, coletados de Guimarães César (2007): a resistência à tração; e o módulo de elasticidade da unidade cerâmica empregada.

Os resultados obtidos durante essa etapa serviram de subsídio para a compreensão do comportamento dos prismas em relação à resistência de aderência à flexão e à compressão, e dos corpos de prova com seção transversal em "H" na presença de tensões de compressão/cisalhamento verticais. Na Tabela 1 são apresentados de forma sintética os dados coletados durante a caracterização dos materiais e componentes.

Os resultados obtidos demonstram que a adoção de um traço rico em aglomerante, de um baixo fator água/aglomerante e de um agregado miúdo com alto teor de finos resultou na confecção de uma argamassa de elevada resistência à compressão e à tração na flexão. Essa alta resistência mecânica induziu a um aumento significativo do módulo de elasticidade, ou seja, uma baixa expressiva da capacidade de deformação da argamassa. Entretanto, ao proporcionar um incremento da resistência à compressão, obteve-se também uma elevação da resistência à tração na flexão, que, segundo Antunes et al. (2010), tem relação direta com a resistência de aderência argamassasubstrato. Durante esses ensaios, constatou-se também que a unidade cerâmica atendeu de modo satisfatório aos requisitos prescritos pela norma brasileira NBR 15270-1 (ABNT, 2005c). 
Tabela 1 - Dados obtidos durante a etapa de caracterização dos materiais e componentes

\begin{tabular}{|c|c|c|c|}
\hline \multicolumn{4}{|c|}{ Resultados obtidos durante o ensaio experimental do agregado miúdo } \\
\hline \multicolumn{4}{|c|}{ Resultados obtidos durante o ensaio de determinação da granulometria } \\
\hline $\begin{array}{l}\text { Peneira com abertura de } \\
\text { malha (ABNT NBR NM } \\
\text { ISO 3310-1) }\end{array}$ & $\begin{array}{l}\text { Massa da areia } \\
\text { retida na peneira } \\
(\mathrm{g})\end{array}$ & $\begin{array}{c}\text { Massa da areia } \\
\text { retida na peneira } \\
(\%)\end{array}$ & $\begin{array}{l}\text { Massa acumulada da areia } \\
\text { retida na peneira }(\%)\end{array}$ \\
\hline $600 \mu \mathrm{m}$ & 14,90 & 1,49 & 1,49 \\
\hline $300 \mu \mathrm{m}$ & 203,90 & 20,39 & 21,88 \\
\hline $150 \mu \mathrm{m}$ & 646,90 & 64,72 & 86,60 \\
\hline $75 \mu \mathrm{m}$ & 127,80 & 12,79 & 99,38 \\
\hline Fundo & 6,20 & 0,62 & 100,00 \\
\hline \multicolumn{3}{|c|}{ Teor médio de matéria orgânica (\%) } & 0,1 \\
\hline \multicolumn{3}{|c|}{ Massa unitária média $\left(\mathrm{kg} / \mathrm{dm}^{3}\right)$} & 1,48 \\
\hline \multicolumn{3}{|c|}{ Massa específica média $\left(\mathrm{kg} / \mathrm{dm}^{3}\right)$} & 2,63 \\
\hline \multicolumn{3}{|c|}{ Coeficiente médio de inchamento médio } & 1,41 \\
\hline \multicolumn{3}{|c|}{ Teor médio de materiais pulverulentos $(\%)$} & 0,31 \\
\hline \multicolumn{4}{|c|}{ Resultados obtidos durante o ensaio experimental da argamassa/graute } \\
\hline \multicolumn{3}{|c|}{ Índice de consistência (mm) } & 182 \\
\hline \multicolumn{3}{|l|}{ Densidade $\left(\mathrm{kg} / \mathrm{dm}^{3}\right)$} & 2,16 \\
\hline \multicolumn{3}{|c|}{ Teor de ar incorporado $(\%)$} & 2,43 \\
\hline \multicolumn{3}{|c|}{ Índice de retenção de água $(\%)$} & 96,14 \\
\hline \multicolumn{3}{|c|}{ Resistência à compressão (MPa) } & 49,07 \\
\hline \multicolumn{3}{|c|}{ Resistência à flexão (MPa) } & 8,09 \\
\hline \multicolumn{3}{|c|}{ Módulo de elasticidade (GPa) } & 26,72 \\
\hline \multicolumn{3}{|c|}{ Coeficiente de Poisson } & 0,1982 \\
\hline \multicolumn{4}{|c|}{ Resultados obtidos durante o ensaio experimental da unidade cerâmica estrutural } \\
\hline \multicolumn{3}{|c|}{ Massa aparente média $(\mathrm{g})$} & 3183,33 \\
\hline \multicolumn{3}{|l|}{ Massa seca média $(\mathrm{g})$} & 5244,17 \\
\hline \multicolumn{3}{|l|}{ Massa úmida média $(\mathrm{g})$} & 6074,17 \\
\hline \multicolumn{3}{|c|}{ Índice médio de absorção de água (\%) } & 16,28 \\
\hline \multicolumn{3}{|c|}{ Índice médio de absorção de água inicial $\left(\left(\mathrm{g} / 193,55 \mathrm{~cm}^{2}\right) / \mathrm{min}\right)$} & 29,44 \\
\hline \multicolumn{3}{|c|}{ Área líquida média $\left(\mathrm{cm}^{2}\right)$} & 153,07 \\
\hline \multicolumn{3}{|c|}{ Resistência à compressão média (MPa) } & 16,09 \\
\hline \multicolumn{3}{|c|}{ Resistência à tração $(\mathrm{MPa})(*)$} & 0,15 \\
\hline \multicolumn{3}{|c|}{ Módulo de elasticidade $(\mathrm{MPa})(*)$} & 4733 \\
\hline \multicolumn{4}{|c|}{ (*) Resultados obtidos por Guimarães (2007) } \\
\hline
\end{tabular}

Finalizados os ensaios anteriores, deu-se início à análise dos prismas de alvenaria em relação à resistência à compressão e à flexão. Para esses ensaios foram confeccionados 6 prismas compostos de três unidades e 6 de quatro unidades, ambos com junta a prumo, conforme as recomendações previstas em normas técnicas (NBR 15270-1 (ABNT, 2005c), NBR 12118 (ABNT, 2010) e E-518 (AMERICAN..., 2003a). Os prismas do primeiro grupo foram utilizados para o ensaio de determinação da resistência à compressão, e os do segundo, para a obtenção da resistência de aderência à tração na flexão. Em ambos os casos as juntas tinham no máximo 5,0 $\mathrm{mm}$ de espessura, pois o objetivo consistiu em avaliar o comportamento da argamassa em situação de uso. Os procedimentos adotados foram norteados por normas brasileiras da ABNT (NBR
8215 (ABNT, 1983), NBR 12118 (ABNT, 2010) e NBR 15961-1 (ABNT, 2011)) e americanas da ASTM (ASTM C-1314 (AMERICAN.., 2003b) e ASTM E-518 (AMERICAN..., 2003 ${ }^{\mathrm{a}}$ )), sendo os resultados obtidos apresentados na Tabela 2.

Os resultados obtidos demonstram que o uso de uma argamassa com 49,07 MPa associada a juntas com espessura média de $5 \mathrm{~mm}$ proporcionam uma melhora ínfima no desempenho do conjunto argamassa-unidade cerâmica em relação à resistência tanto à compressão quanto de aderência à tração na flexão. Esses fatores ainda contribuíram para que o conjunto assumisse um comportamento frágil, ocasionado pela diminuição da capacidade da argamassa de acomodar as deformações (módulo de elasticidade de 26,72 $\mathrm{GPa})$. 
Tabela 2 - Resultados obtidos durante a etapa de avaliação dos prismas de alvenaria

\begin{tabular}{c|c|c}
\hline Carga aplicada média $(\mathbf{k N})$ & $\begin{array}{c}\text { Resistência à compressão } \\
\text { Área líquida média }(\mathbf{M P a})\end{array}$ & $\begin{array}{c}\text { Resistência à compressão } \\
\text { Área bruta média }(\mathbf{M P a})\end{array}$ \\
\hline $\mathbf{2 9 1 , 3}$ & $\mathbf{1 7 , 0 6}$ & $\mathbf{7 , 6 7}$ \\
\hline \multicolumn{2}{c|}{ Resistência de aderência à tração na flexão média $(\mathrm{MPa})$} & $\mathbf{0 , 6 2}$ \\
\hline
\end{tabular}

\section{Programa experimental}

Esta etapa corresponde à investigação experimental do modelo abordado de conexão vertical de painéis estruturais cerâmicos préfabricados. A geometria do corpo de prova e a forma de aplicação do carregamento e do posicionamento dos apoios, ou seja, o procedimento de ensaio adotado encontra-se fundamentado em pesquisas desenvolvidas desde 1979 por autores como Sinha e Hendry (1979) e visam avaliar o comportamento das interfaces de paredes em alvenaria estrutural. A geometria adotada nesta etapa (Figura 1) consiste basicamente na junção de cinco prismas de quatro fiadas, sendo a última fiada antecedida por uma placa confeccionada em argamassa com $20 \mathrm{~mm}$ de espessura, armada por uma fina tela metálica em camada dupla, com o intuito de minimizar a ocorrência de fissuras.

Na confecção dos pequenos prismas foi empregada a família de unidades cerâmicas estruturais de 140 $\mathrm{mm}$ de largura, sendo utilizadas as unidades com $140 \mathrm{~mm}, 290 \mathrm{~mm}$ e $440 \mathrm{~mm}$ de comprimento. Em relação à espessura das juntas de argamassa, destaca-se que a horizontal foi realizada com aproximadamente $5 \mathrm{~mm}$, e a vertical, com $10 \mathrm{~mm}$ (adequação necessária para atender aos requisitos referentes à geometria). Nos pontos onde ocorrem as junções dos prismas, as unidades cerâmicas sofreram recortes especiais, sendo o espaço resultante desse processo posteriormente preenchido com a argamassa de assentamento e armado por uma estrutura metálica executada com barras de $10 \mathrm{~mm}$ de diâmetro.

A aplicação da carga ocorreu em um único ciclo, de forma lenta e contínua, somente sobre o painel central do corpo de prova com seção transversal em "H", cujos painéis externos encontravam-se devidamente apoiados no solo enquanto o painel central estava engastado aos laterais, sem encostarse ao solo. Esse procedimento de ensaio visou representar o comportamento da interface dos painéis submetidos à presença de tensões verticais de cisalhamento por meio da indução de deslizamento vertical em sua interseção, as quais podem ser ocasionadas pela existência de cargas tanto verticais quanto horizontais.

Para a realização desse ensaio foram utilizados sete transdutores indutivos de deslocamento com capacidade de medição entre $10 \mathrm{~mm}$ e $20 \mathrm{~mm}$, uma célula de carga e um pistão hidráulico, ambos com capacidade máxima de $200 \mathrm{kN}$, um equipamento para aquisição de dados HBM Spider 8 e um computador. Os transdutores de deslocamento foram posicionados conforme o esquema ilustrado na Figura 2, sendo o esquema $2 \mathrm{~A}$ empregado no primeiro ensaio, e o $2 \mathrm{~B}$, nos outros dois. Em ambos os casos, tanto o ponto inferior quanto o superior de medição foram dispostos a $95 \mathrm{~mm}$ das bordas superiores e inferiores do prisma. Os apoios foram colocados apenas sob os painéis externos, para que o painel central permanecesse livre para se deslocar, conforme ilustrado na Figura 3.

As médias dos resultados obtidos nessa etapa encontram-se apresentadas na Tabela 3 e representadas graficamente na Figura 4. Em todos os casos constatou-se a presença de fissuras no painel central e em alguns dos painéis externos, ocasionadas pela presença de forças de tração. Outro fato observado durante a análise dos resultados foi uma possível falha da junção do prisma externo situado junto ao transdutor de deslocamento 07 , pois os dados obtidos demonstram que houve um deslocamento positivo, indicando um descarregamento. Isso ocorreu devido a uma tendência de tombamento do prisma central, induzido pela assimetria dos "dutos" de argamassa (conexão com formato em "L") em relação ao plano do prisma central, na direção dos prismas da extremidade, confeccionados com unidades cerâmicas de $440 \mathrm{~mm}$ de comprimento. Esse fato foi também confirmado pela análise numérica. 


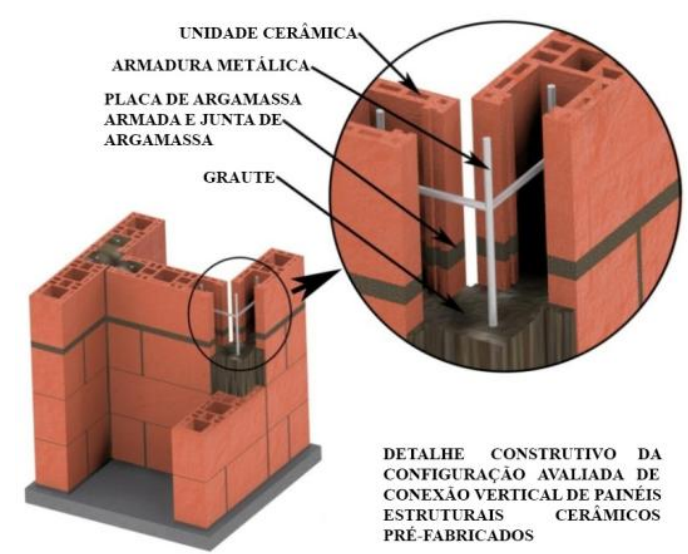

Figura 1 - Detalhe construtivo do modelo avaliado de conexão vertical de painéis estruturais cerâmicos pré-fabricados

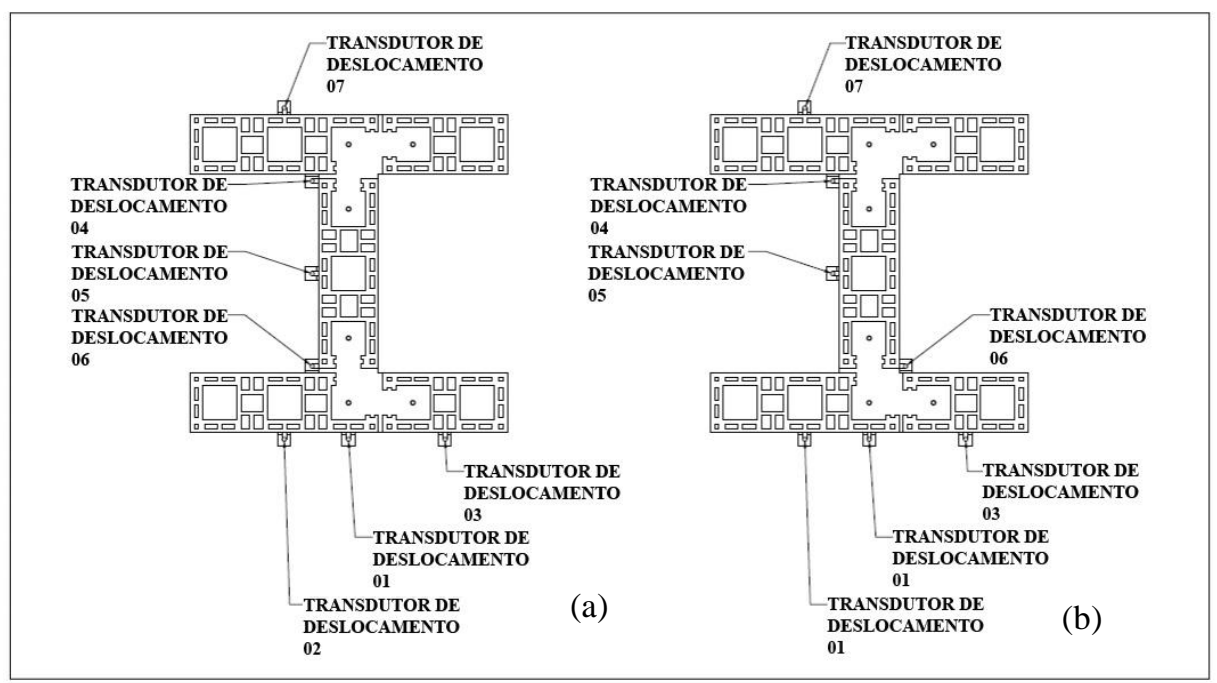

Figura 2 - Esquema de instrumentação do ensaio do corpo de prova com seção transversal em " $\mathrm{H}$ " Nota: (a) Esquema utilizado no ensaio do primeiro corpo de prova e (b) esquema utilizado no ensaio do segundo e do terceiro corpos de prova.
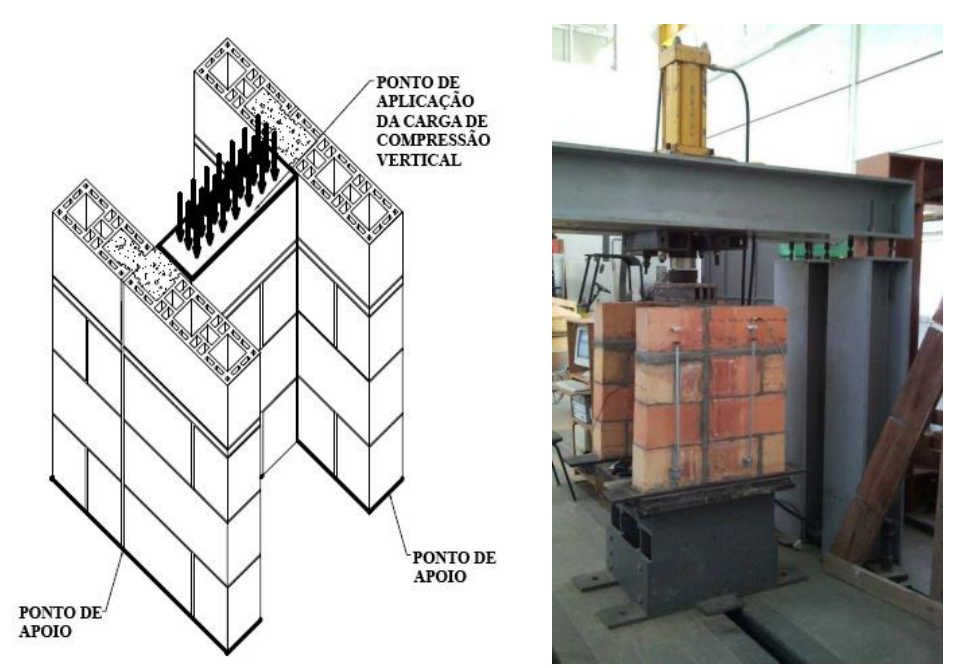

Figura 3 - Ensaio do corpo de prova com seção transversal em "H"

Nota: a ilustração da esquerda apresenta esquematicamente a aplicação do carregamento e o posicionamento dos apoios e a da direita, o procedimento de ensaio.

40 Manzano, R. de M.; Roman, H. R.; Gómez, L. A. 
Tabela 3 - Média dos resultados obtidos durante a execução do ensaio experimental dos corpos de prova com seção transversal em "H"

\begin{tabular}{|c|c|c|c|c|c|c|c|c|}
\hline $\begin{array}{c}\text { Carga } \\
(\mathbf{k N})\end{array}$ & $\begin{array}{l}\text { Tensão p/ } \\
\text { área líquida } \\
\text { do painel } \\
\text { central } \\
\text { (MPa) }\end{array}$ & $\begin{array}{l}\text { Transd. } 01 \\
\quad(\mathrm{~mm})\end{array}$ & $\begin{array}{l}\text { Transd. } 02 \\
\text { (mm) }\end{array}$ & $\begin{array}{l}\text { Transd. } 03 \\
\quad(\mathrm{~mm})\end{array}$ & $\begin{array}{l}\text { Transd. } 04 \\
\text { (mm) }\end{array}$ & $\begin{array}{l}\text { Transd. } 05 \\
\quad(\mathrm{~mm})\end{array}$ & $\begin{array}{l}\text { Transd. } 06 \\
\quad(\mathrm{~mm})\end{array}$ & $\begin{array}{c}\text { Transd. } 07 \\
(\mathbf{m m})\end{array}$ \\
\hline 4 & 0,09 & 0,0001 & $-0,0005$ & $-0,0008$ & $-0,0024$ & $-0,0008$ & $-0,0016$ & $-0,0000$ \\
\hline 8 & 0,19 & $-0,0004$ & $-0,0015$ & $-0,0015$ & $-0,0046$ & $-0,0019$ & $-0,0041$ & $-0,0000$ \\
\hline 24 & 0,56 & $-0,0030$ & $-0,0013$ & $-0,0038$ & $-0,0156$ & $-0,0077$ & $-0,0116$ & $-0,0000$ \\
\hline 28 & 0,65 & $-0,0038$ & $-0,0014$ & $-0,0044$ & $-0,0188$ & $-0,0093$ & $-0,0130$ & $-0,0000$ \\
\hline 34 & 0,79 & $-0,0058$ & $-0,0017$ & $-0,0053$ & $-0,0235$ & $-0,0117$ & $-0,0157$ & $-0,0000$ \\
\hline 40 & 0,93 & $-0,0069$ & $-0,0014$ & $-0,0067$ & $-0,0283$ & $-0,0144$ & $-0,0184$ & $-0,0000$ \\
\hline 44 & 1,03 & $-0,0081$ & $-0,0015$ & $-0,0071$ & $-0,0314$ & $-0,0161$ & $-0,0204$ & $-0,0038$ \\
\hline 48 & 1,12 & $-0,0094$ & $-0,0030$ & $-0,0077$ & $-0,0343$ & $-0,0179$ & $-0,0222$ & $-0,0038$ \\
\hline 74 & 1,73 & $-0,0143$ & $-0,0087$ & $-0,0088$ & $-0,0593$ & $-0,0226$ & $-0,0425$ & 0,0075 \\
\hline 80 & 1,87 & $-0,0163$ & $-0,0105$ & $-0,0094$ & $-0,0647$ & $-0,0225$ & $-0,0456$ & 0,0037 \\
\hline
\end{tabular}

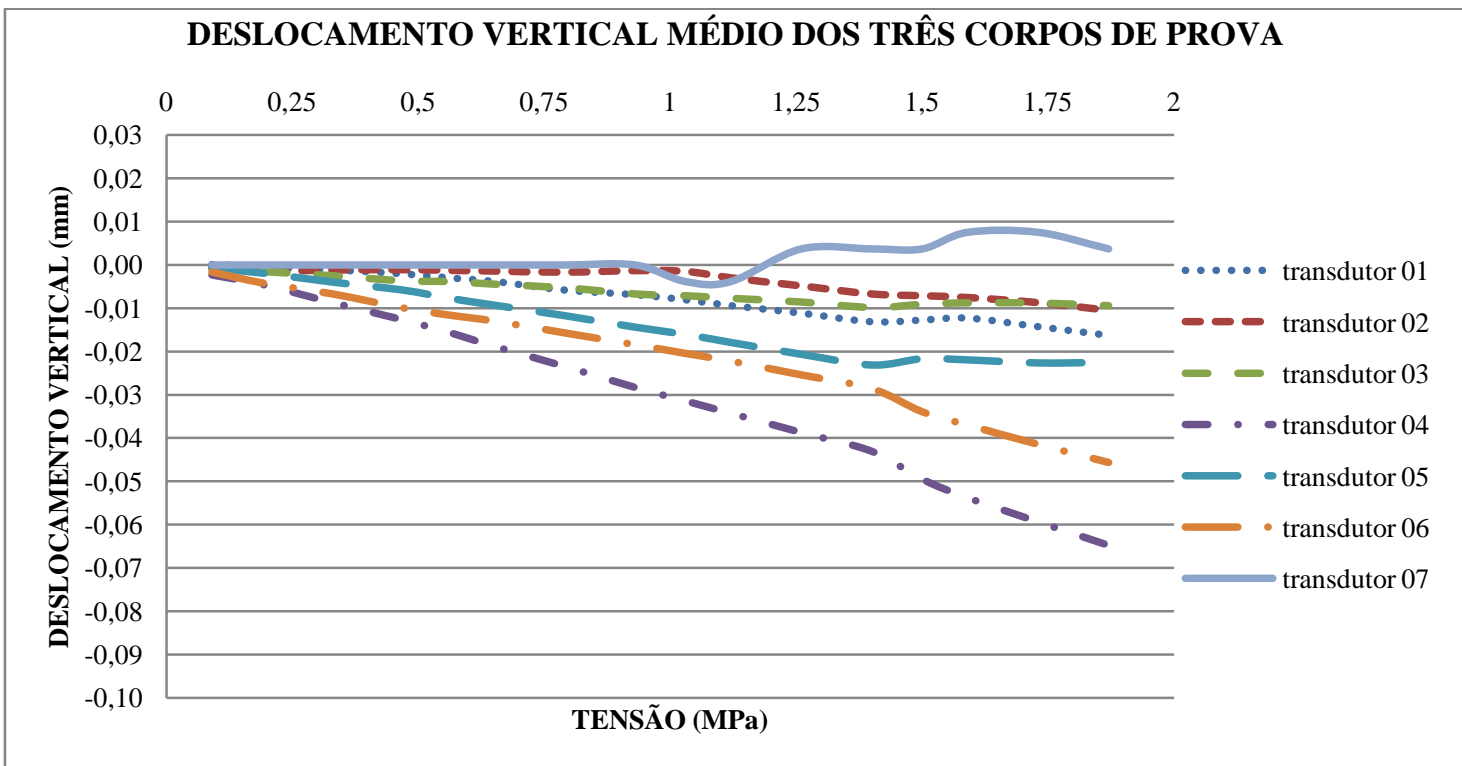

Figura 4 - Representação gráfica dos dados apresentados na Tabela 3

Nota: o eixo das abscissas corresponde à tensão para área líquida do painel central.

Os recortes realizados nas unidades cerâmicas situadas nas extremidades dos prismas contribuíram para o desempenho da conexão, pois ampliaram a área de contato argamassa-substrato, minimizando as influências negativas da alta capacidade de retenção de água e do baixo fator água-aglomerante da argamassa. Esse ganho de desempenho pode ser atribuído também à presença de uma armadura metálica, pois o uso desta, ainda que em menor intensidade, contribui para o aumento da rigidez da conexão.

Em seguida, com base no método proposto por Guimarães César (2007), determinou-se a parcela da carga recebida por cada material constituinte do prisma em relação à área líquida do painel central e do prisma em formato " $\mathrm{H}$ ". Os resultados apresentados na Tabela 4 demonstram que o desempenho da argamassa atua de modo significativo sobre o comportamento da conexão, sendo sua influência superior a da armadura metálica. Esses dados também demonstram que o tipo de aço empregado na armadura promove alterações mínimas na parcela de carga absorvida por cada material. No caso em que a armadura foi desconsiderada, a argamassa foi responsável pela recepção da maior parcela da carga destinada a esta. 
Tabela 4 - Análise da absorção da carga aplicada pelos materiais componentes do corpo de prova com seção transversal "H"

\begin{tabular}{|c|c|c|c|c|c|c|}
\hline \multicolumn{7}{|c|}{ Corpo de prova com seção transversal em "H" confeccionado com aço CA-50 } \\
\hline & \multicolumn{6}{|c|}{ Área líquida do prisma central } \\
\hline $\begin{array}{l}\text { Materiais e } \\
\text { componentes }\end{array}$ & $\begin{array}{c}\text { Carga } \\
\text { aplicada }\end{array}$ & $\begin{array}{l}\text { Módulo de } \\
\text { elasticidade } \\
\text { (GPa) }\end{array}$ & $\begin{array}{c}\text { Carga } \\
\text { absorvida } \\
(\mathbf{k N})\end{array}$ & $\begin{array}{c}\text { Carga } \\
\text { absorvida } \\
(\%)\end{array}$ & $\begin{array}{c}\text { Área } \\
\text { líquida } \\
(\%)\end{array}$ & $\begin{array}{l}\text { Tensão } \\
\text { (MPa) }\end{array}$ \\
\hline Unidade cerâmica & \multirow[b]{3}{*}{ 1,40 MPa } & 4,733 & 12,48 & 20,79 & 61,21 & 0,48 \\
\hline Argamassa & & 26,720 & 44,21 & 73,68 & 38,42 & 2,69 \\
\hline Aço da armadura & & 210,000 & 3,32 & 5,53 & 0,37 & 21,13 \\
\hline
\end{tabular}

Corpo de prova com seção transversal em "H" confeccionado com aço CA-25

\begin{tabular}{l|c|c|c|c|c|c}
\hline Unidade cerâmica & \multirow{2}{*}{$60 \mathrm{kN}$} & 4,733 & 12,49 & 20,82 & 61,21 & 0,48 \\
\cline { 1 - 5 } Argamassa & & 26,720 & 44,26 & 73,77 & 38,42 & 2,69 \\
\cline { 1 - 4 } Aço da armadura & $1,40 \mathrm{MPa}$ & 205,000 & 3,24 & 5,40 & 0,37 & 20,65 \\
\cline { 3 - 6 }
\end{tabular}

Corpo de prova com seção transversal em "H", desconsiderando-se a presença da armadura metálica

\begin{tabular}{l|c|c|c|c|c|c}
\hline Unidade cerâmica & $60 \mathrm{kN}$ & 4,733 & 13,11 & 21,85 & 61,21 & 0,50 \\
\cline { 1 - 4 } Argamassa & $1,40 \mathrm{MPa}$ & 26,720 & 46,89 & 78,15 & 38,79 & 2,82 \\
\hline
\end{tabular}

Ao final, com a adoção do procedimento proposto por Capuzzo Neto (2005) e do valor médio de ruptura constatada no transdutor de deslocamento 07, obteve-se a resistência ao cisalhamento vertical do modelo de conexão abordado. O procedimento adotado considera que a resistência média ao cisalhamento é igual à razão da força de ruptura do corpo de prova pela área das interseções. A aplicação desse procedimento resultou na obtenção de uma resistência de aproximadamente $0,28 \mathrm{MPa}$, ou seja, bem abaixo do 0,37 $\mathrm{MPa}$ recomendado pela atual norma NBR 15961-1 (ABNT, 2011) (Alvenaria estrutural - Blocos de Concreto. Parte 1: Projeto.) para peças em alvenaria confeccionadas com amarração direta e armaduras perpendiculares ao plano de cisalhamento, envoltas por graute, submetidas à flexão, porém dentro do esperado para amarrações indiretas da alvenaria, ou seja, aproximadamente $40 \%$ da resistência média da amarração direta obtida em diversas pesquisas $(0,70 \mathrm{MPa})$.

\section{Análise numérica pelo método de elementos finitos}

O desenvolvimento desta análise teve por intuito compreender a distribuição das tensões normais verticais e a influência da argamassa e da armadura metálica no desempenho do modelo avaliado de conexão vertical. A metodologia empregada nesta etapa teve por base os procedimentos de análise dos deslocamentos e das tensões pelo Método de Elementos Finitos da interseção entre painéis estruturais cerâmicos pré-fabricados (corpo de prova com seção transversal em "H", visando representar a união entre cinco painéis distintos) quando submetidos a esforços de compressão/cisalhamento vertical. Para tal avaliação foram consideradas as hipóteses de isotropia, homogeneidade e não linearidade física dos materiais, sendo utilizado para esse processo o software ANSYS.

Nesta etapa foram concebidos dois modelos numéricos tridimensionais distintos, sendo o primeiro confeccionado com os apoios situados apenas sob os prismas da extremidade (painéis externos), e o segundo executado de modo a considerar a base do corpo de prova completamente apoiada. O modelo geométrico elaborado consistiu em uma representação verossímil do corpo de prova, ou seja, com todos os furos e recortes existentes nas unidades cerâmicas, com a espessura da camada de argamassa executada entre as unidades, com a geometria final assumida pelo graute e com a configuração tridimensional da armadura metálica. Em outras palavras, para a realização desta análise foi adotada a micromodelagem simplificada. Porém, nesses modelos não foi considerado o comportamento das interfaces bloco-argamassa e argamassa-armadura, ou seja, considerou-se a perfeita aderência entre os elementos, fato esse que atendeu de modo adequado ao objetivo deste estudo. Para simular a perfeita aderência foram adotados os elementos tridimensionais de contato CONTA174 e TARGE170, ambos compostos de 8 nós, com contato do tipo superfície-superfície. Nesta análise consideraram-se também os nós posicionados no meio das arestas. A aplicação da carga ao topo do prisma central (painel central) foi intermediada por uma viga de aço, confeccionada com base nas características geométricas da viga 
utilizada durante o ensaio. O uso desse elemento visou representar com fidelidade a situação real durante o programa experimental.

Com a conclusão da geometria, deu-se início ao processo de inserção das propriedades dos materiais a serem utilizados na análise numérica, ou seja, das propriedades referentes à argamassa, a unidade cerâmica estrutural e aos dois tipos de aços utilizados, conforme os dados apresentados na Tabela 5. Entre todas as propriedades abordadas, somente o coeficiente de Poisson do bloco cerâmico foi arbitrado, com base na norma brasileira NBR 15270-1 (ABNT, 2005c). Os demais dados foram obtidos através de ensaio experimental, da revisão bibliográfica e do próprio software (dados gerados de forma automática com a inserção de algumas propriedades).

As cargas ou carregamentos abordados nos modelos numéricos foram a força da gravidade sendo sua influência considerada sobre o corpo de prova e a viga - e o carregamento vertical concentrado sobre a viga de aço posicionada no topo do prisma central do corpo de prova com seção transversal em "H". As condições de contorno, por sua vez, se resumiram a duas formas distintas de apoio, sendo realizada a restrição tanto dos deslocamentos quanto das rotações dos nós situados junto aos pontos de apoio. Esses procedimentos foram embasados nos métodos adotados na área da Engenharia Mecânica e no manual do software, os quais prescrevem o coeficiente de atrito igual a 1 para o contato entre superfícies rugosas e a borracha e a perfeita aderência para coeficientes de atrito entre 1 e 4 . A disposição dos apoios e a forma de aplicação da carga concentrada encontram-se ilustradas na Figura 5.

Em seguida, foram definidos os tipos de elementos estruturais e a malha a serem utilizados. Nesse caso, optou-se pelo emprego dos elementos SOLID186 (hexaédrico de 20 nós) e SOLID187 (tetraédrico de 10 nós), ambos com três graus de liberdade por nó. A calibração do modelo numérico concebido teve como referência a média dos deslocamentos verticais médios obtidos pelos setes transdutores durante o ensaio experimental. A precisão dos resultados foi sendo aprimorada com o refinamento da malha utilizada. Porém, o ganho de precisão promovido pelo nível de refinamento foi limitado pelo aporte tecnológico disponível. Desse modo, a malha que atendeu tanto ao aporte tecnológico disponível quanto à precisão almejada foi a com arestas entre $3 \mathrm{~mm}$ e $5 \mathrm{~mm}$. Os resultados obtidos são apresentados na Figura 6.

Tabela 5 - Materiais utilizados na análise numérica do corpo de prova com seção transversal em "H"

\begin{tabular}{|c|c|c|c|c|}
\hline & $\begin{array}{c}\text { Aço } \\
\text { estrutura } \\
\text { CA-50 } \\
\end{array}$ & $\begin{array}{c}\text { Aço } \\
\text { estrutura } \\
\text { CA-25 } \\
\end{array}$ & $\begin{array}{c}\text { Argamassa de } \\
\text { assentamento e } \\
\text { grauteamento }\end{array}$ & $\begin{array}{c}\text { Unidade } \\
\text { cerâmica } \\
\text { estrutural } \\
\end{array}$ \\
\hline Densidade $\left(\mathrm{kg} / \mathrm{m}^{3}\right)$ & 7.850 & 7.850 & 2.155 & 1.550 \\
\hline Poisson & 0,3 & 0,3 & 0,1982 & $0,16^{(4)}$ \\
\hline Módulo de elasticidade (GPa) & 210 & 205 & 26,72 & $4,733^{(2)}$ \\
\hline Modulo de massa (GPa) & $175^{(3)}$ & $170,83^{(3)}$ & $14,756^{(3)}$ & $2,3201^{(3)}$ \\
\hline Módulo de cisalhamento (GPa) & $80,769^{(3)}$ & $78,846^{(3)}$ & $11,15^{(3)}$ & $2,0401^{(3)}$ \\
\hline Elasticidade a compressão (GPa) & $1,45^{(3)}$ & $1,45^{(3)}$ & - & - \\
\hline Resistência limite à tração $(\mathrm{MPa})$ & 500 & 250 & 0 & 0 \\
\hline $\begin{array}{l}\text { Resistência limite à compressão } \\
\text { (MPa) }\end{array}$ & 500 & 250 & 0 & 0 \\
\hline Resistência última à tração (MPa) & 540 & 300 & 9,06 & $0,16^{(2)}$ \\
\hline $\begin{array}{l}\text { Resistência última à compressão } \\
\text { (MPa) }\end{array}$ & 0 & 0 & 49,07 & 8,33 \\
\hline
\end{tabular}

Fonte: Gerdau (2012), Guimarães César (2007) e Ansys (2011).

Nota: ${ }^{(1)}$ Fonte: Gerdau (2012).

(2) Fonte: Guimarães César (2007).

(3) Fonte: Ansys software (2011), que se refere aos dados gerados pelo software.

(4) Fonte: estabelecido com base nas recomendações da norma brasileira NBR 15270-1 (ABNT, 2005C) (Coeficiente de Poisson da Alvenaria - 0,15). 

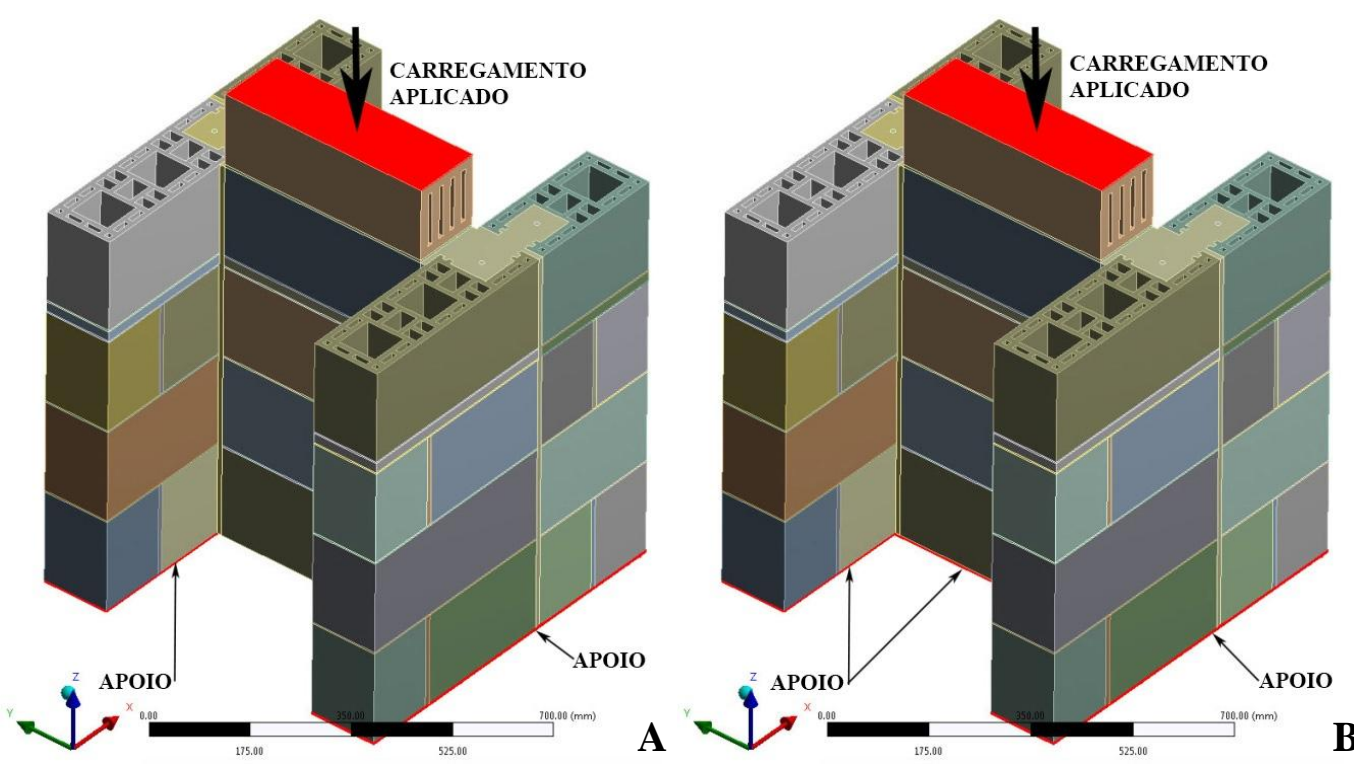

Figura 5 - Modelos numéricos tridimensionais do corpo de prova com seção transversal em "H"

Nota: o esquema A corresponde ao modelo confeccionado com o prisma central engastado aos da extremidade com sua borda inferior livre e com armadura metálica executada em aço CA-50 e em aço CA-25, e o esquema B, ao modelo com armadura em aço CA-50 com sua base completamente apoiada.

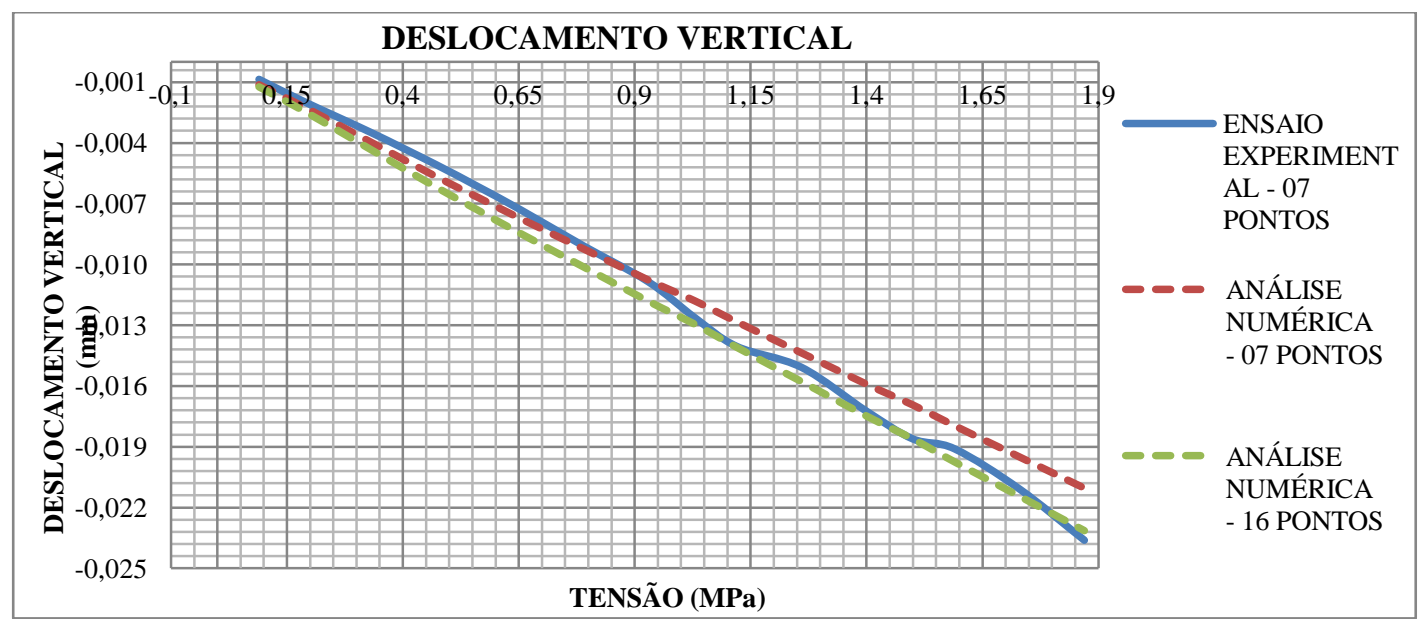

Figura 6 - Deslocamento vertical

Finalizado o processo de calibração do modelo numérico, buscou-se avaliar qual a influência do tipo de aço utilizado na confecção da armadura metálica e da disposição dos apoios sob a base do corpo de prova nos deslocamentos verticais. Dessas simulações resultaram os dados apresentados na Tabela 6. Esses dados demonstram que, para o traço adotado da argamassa de assentamento/grauteamento, a alteração do tipo de aço utilizado na confecção da armadura metálica promove mudanças ínfimas no deslocamento vertical. Entretanto, o mesmo não se observa com relação à disposição dos apoios, pois sua modificação induz alterações expressivas no comportamento do corpo de prova. Essa mudança de comportamento fica evidente pelos dados apresentados na Tabela 6 e nas imagens expostas na Figura 7, pois estes mostram uma diferença significativa entre os deslocamentos verticais obtidos no prisma central (painel central) de ambas as disposições de apoio. Durante a análise numérica, constatou-se também a existência de deslocamento vertical positivo dos prismas confeccionados com unidades cerâmicas estruturais de $290 \mathrm{~mm}$ de comprimento em todos os modelos (CA-50, CA-25 e CA-50 com sua base completamente apoiada), conforme ilustrado na Figura 7. Em outras palavras, assimetria dos "dutos" em relação ao plano do prisma central (formato em " $\mathrm{L}$ ") induz a uma excentricidade na distribuição da carga aplicada ao prisma central. 
Tabela 6 - Deslocamento vertical dos corpos de prova confeccionados com aço CA-50 e CA-25 com prisma central engastado aos da extremidade e sua borda inferior livre, e CA-50 com a base completamente apoiada

\begin{tabular}{|c|c|c|c|c|}
\hline \multicolumn{5}{|c|}{ Resultados referentes ao deslocamento vertical } \\
\hline & $\begin{array}{c}\text { Carga aplicada } \\
(\mathbf{k N})\end{array}$ & $\begin{array}{c}\text { Aço CA-50 } \\
(\mathrm{mm})\end{array}$ & $\begin{array}{c}\text { Aço CA-25 } \\
(\mathrm{mm})\end{array}$ & $\begin{array}{c}\text { Aço CA-50 com a base } \\
\text { totalmente apoiada }\end{array}$ \\
\hline PATH 01 & \multirow{16}{*}{60} & $-0,0148$ & $-0,0148$ & $-0,0119$ \\
\hline PATH 02 & & $-0,0018$ & $-0,0018$ & $-0,0004$ \\
\hline PATH 03 & & $-0,0167$ & $-0,0167$ & $-0,0139$ \\
\hline PATH 04 & & $-0,0135$ & $-0,0135$ & $-0,0118$ \\
\hline PATH 05 & & $-0,0017$ & $-0,0017$ & $-0,0005$ \\
\hline PATH 06 & & $-0,0167$ & $-0,0167$ & $-0,0138$ \\
\hline PATH 07 & & $-0,0151$ & $-0,0151$ & $-0,0147$ \\
\hline PATH 08 & & $-0,0234$ & $-0,0235$ & $-0,0225$ \\
\hline PATH 09 & & $-0,0271$ & $-0,0271$ & $-0,0284$ \\
\hline PATH 10 & & $-0,0185$ & $-0,0186$ & $-0,0195$ \\
\hline PATH 11 & & $-0,0149$ & $-0,0149$ & $-0,0143$ \\
\hline PATH 12 & & $-0,0233$ & $-0,0233$ & $-0,0223$ \\
\hline PATH 13 & & $-0,0268$ & $-0,0268$ & $-0,0281$ \\
\hline PATH 14 & & $-0,0183$ & $-0,0183$ & $-0,0193$ \\
\hline PATH 15 & & $-0,0200$ & $-0,0200$ & $-0,0273$ \\
\hline PATH 16 & & $-0,0270$ & $-0,0270$ & $-0,0355$ \\
\hline $\begin{array}{l}\text { Média }(16 \\
\text { pontos) }\end{array}$ & 60 & $-0,0175$ & $-0,0175$ & $-0,0178$ \\
\hline PATH 01 & \multirow{16}{*}{80} & $-0,0196$ & $-0,0196$ & $-0,0157$ \\
\hline PATH 02 & & $-0,0023$ & $-0,0023$ & $-0,0004$ \\
\hline PATH 03 & & $-0,0220$ & $-0,0221$ & $-0,0187$ \\
\hline PATH 04 & & $-0,0178$ & $-0,0178$ & $-0,0156$ \\
\hline PATH 05 & & $-0,0021$ & $-0,0021$ & $-0,0005$ \\
\hline PATH 06 & & $-0,0220$ & $-0,0220$ & $-0,0183$ \\
\hline PATH 07 & & $-0,0199$ & $-0,0200$ & $-0,0195$ \\
\hline PATH 08 & & $-0,0310$ & $-0,0311$ & $-0,0297$ \\
\hline PATH 09 & & $-0,0359$ & $-0,0359$ & $-0,0377$ \\
\hline PATH 10 & & $-0,0246$ & $-0,0246$ & $-0,0258$ \\
\hline PATH 11 & & $-0,0197$ & $-0,0198$ & $-0,0196$ \\
\hline PATH 12 & & $-0,0309$ & $-0,0309$ & $-0,0295$ \\
\hline PATH 13 & & $-0,0355$ & $-0,0355$ & $-0,0373$ \\
\hline PATH 14 & & $-0,0243$ & $-0,0243$ & $-0,0255$ \\
\hline PATH 15 & & $-0,0266$ & $-0,0266$ & $-0,0362$ \\
\hline PATH 16 & & $-0,0359$ & $-0,0359$ & $-0,0471$ \\
\hline $\begin{array}{c}\text { Média (16 } \\
\text { pontos) }\end{array}$ & 80 & $-0,0231$ & $-0,0232$ & $-0,0235$ \\
\hline
\end{tabular}

Nota: as células com a cor semelhante às do corpo de prova confeccionado com aço CA-50 possuem o mesmo valor para o deslocamento vertical; as com a cor mais escura apresentam deslocamento maior; e as sem preenchimento mostram deslocamento menor.

Os resultados apresentados graficamente nas Figuras 8 e 9 demonstram que o modelo avaliado de conexão vertical oferece rigidez suficiente para induzir a interação entre o prisma central (painel central) e os prismas da extremidade (painéis externos). Esse fato foi observado tanto nos gráficos referentes ao deslocamento vertical (Figura 8) quanto nos gráficos relativos às tensões normais (Figura 9), ambos coletados ao longo da altura do corpo de prova durante a aplicação de um carregamento de $60 \mathrm{kN}$. Nas imagens B de ambas as Figuras constata-se uma tendência de convergência tanto dos deslocamentos verticais quanto das tensões normais verticais junto à base do corpo de prova com seção transversal em "H", indicando a homogeneização de ambos nesse ponto. No caso das paredes em alvenaria estrutural, a presença da interação contribui para a ampliação da capacidade de carga de cada parede. Com base nesse comentário e na similaridade do 
processo construtivo abordado com a alvenaria estrutural não armada, conclui-se que o mesmo tenderá a ocorrer, porém sua intensidade dependerá do desempenho da argamassa.

Para a compreensão da forma de ruptura do corpo de prova durante o ensaio experimental geraram-se os gráficos tridimensionais apresentados na Figura 10. Esses gráficos referem-se às tensões principais máximas e abordam as tensões de tração e compressão induzidas tanto pela junta de argamassa quanto pela borda inferior livre do prisma central do corpo de prova durante a aplicação do carregamento de $60 \mathrm{kN}$. Esses gráficos mostram a presença das tensões de tração junto à base do prisma central (painel central) e no terço médio de um dos prismas da extremidade (painéis externos), pontos em que foram constatadas as primeiras fissuras durante a realização do ensaio.
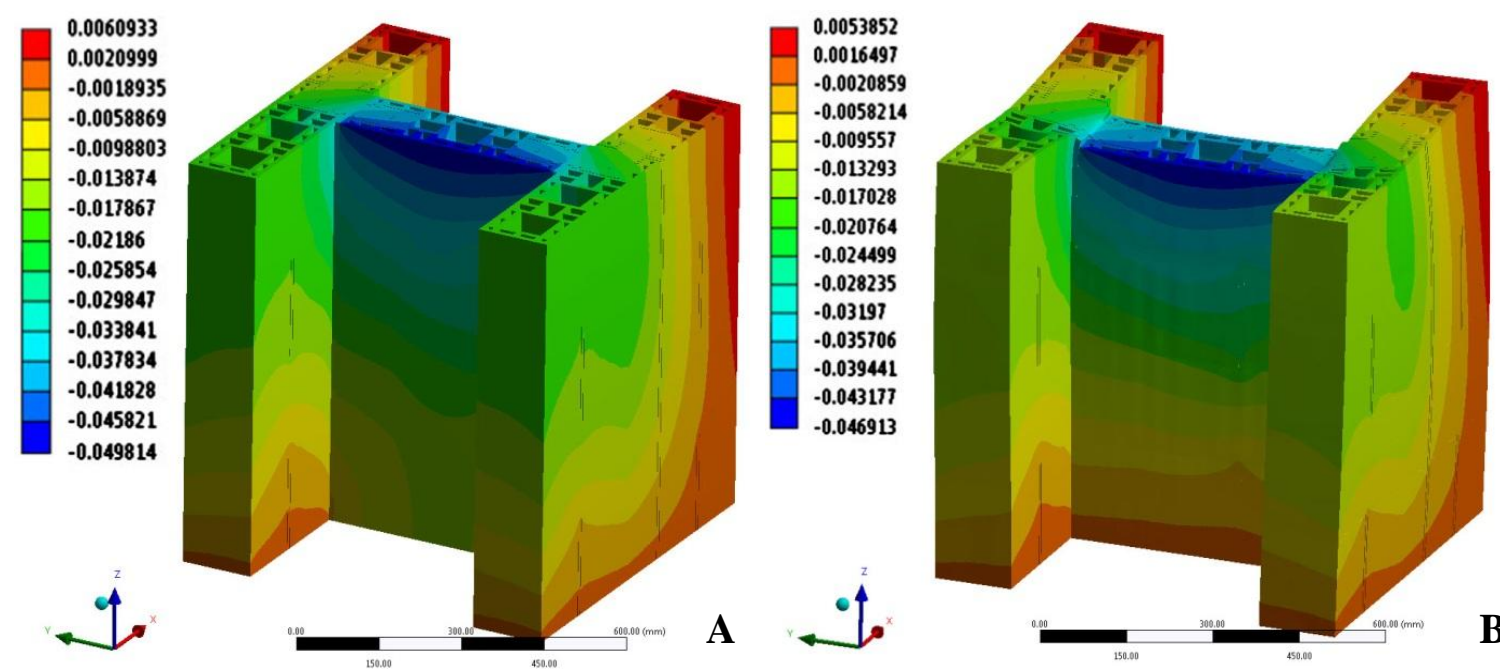

Figura 7 - Deslocamento vertical ao longo da altura do corpo de prova confeccionado com armadura em aço CA-50 durante a aplicação de um carregamento de $60 \mathrm{kN}$

Nota: o gráfico A corresponde ao corpo de prova com os apoios situados apenas sob seus prismas da extremidade (painéis externos), e a imagem $B$, ao corpo de prova com sua base completamente apoiada.
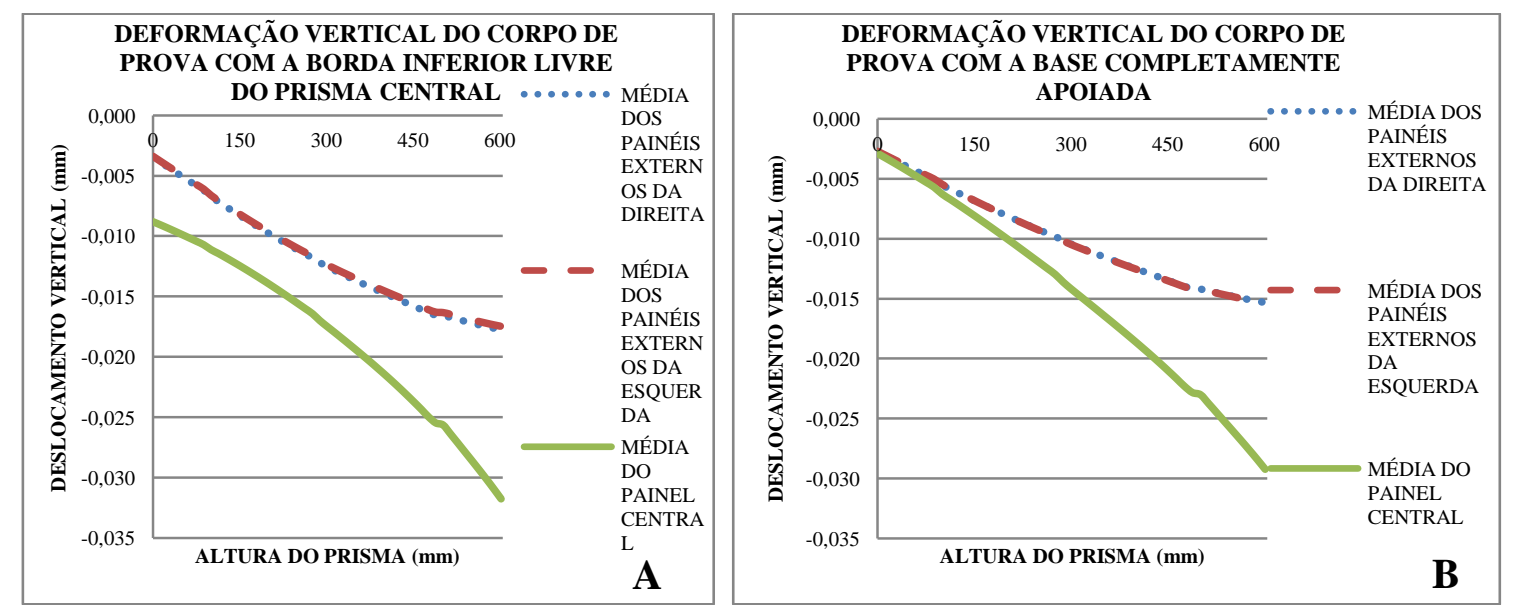

Figura 8 - Deslocamento vertical ao longo da altura do corpo de prova confeccionado com armadura em aço CA-50 durante a aplicação de um carregamento de $60 \mathrm{kN}$

Nota: a imagem A corresponde ao corpo de prova com os apoios situados apenas sob seus prismas da extremidade (painéis externos), e a imagem $B$, ao corpo de prova com sua base completamente apoiada. 

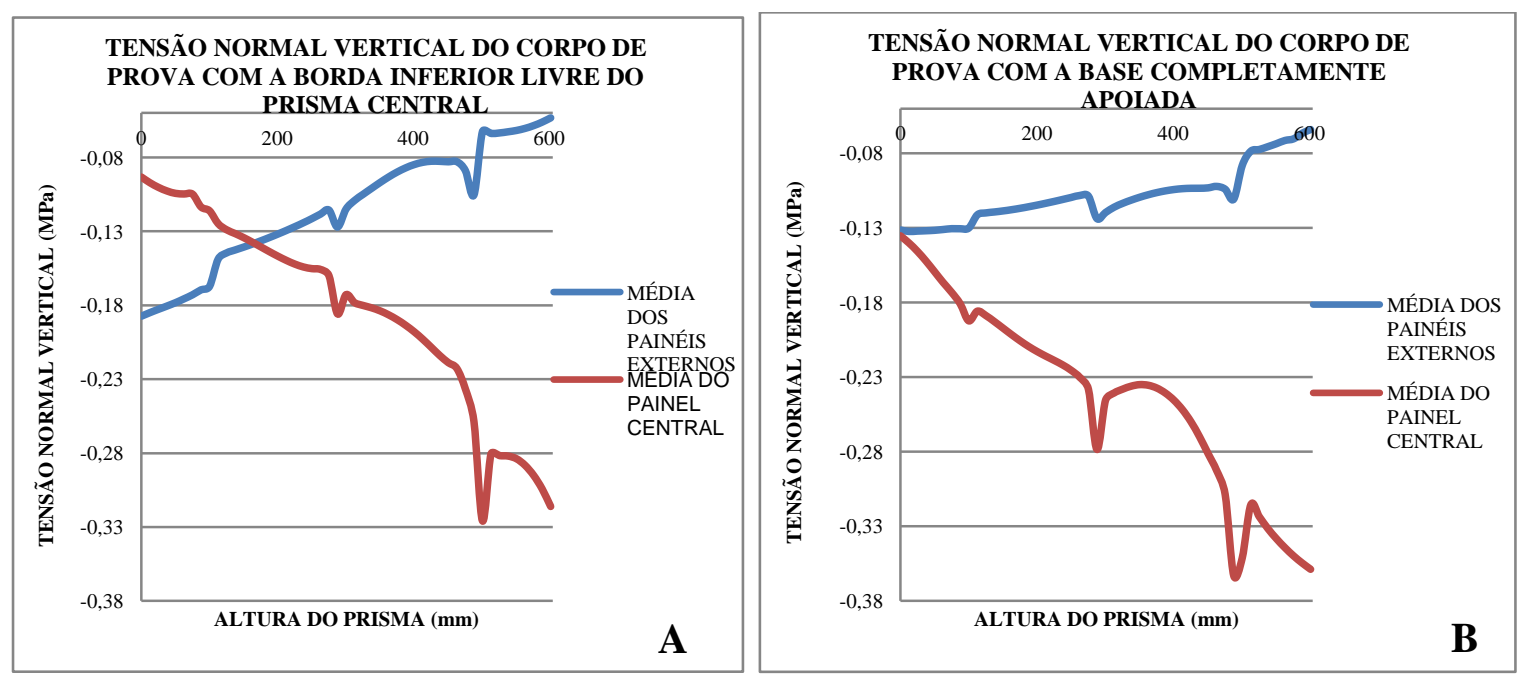

Figura 9 - Tensão normal vertical ao longo da altura do corpo de prova confeccionado com armadura em aço CA-50 durante a aplicação de um carregamento de 60 kN

Nota: o gráfico A corresponde ao corpo de prova com os apoios situados apenas sob seus prismas da extremidade (painéis externos), e a imagem $\mathrm{B}$, ao corpo de prova com sua base completamente apoiada.
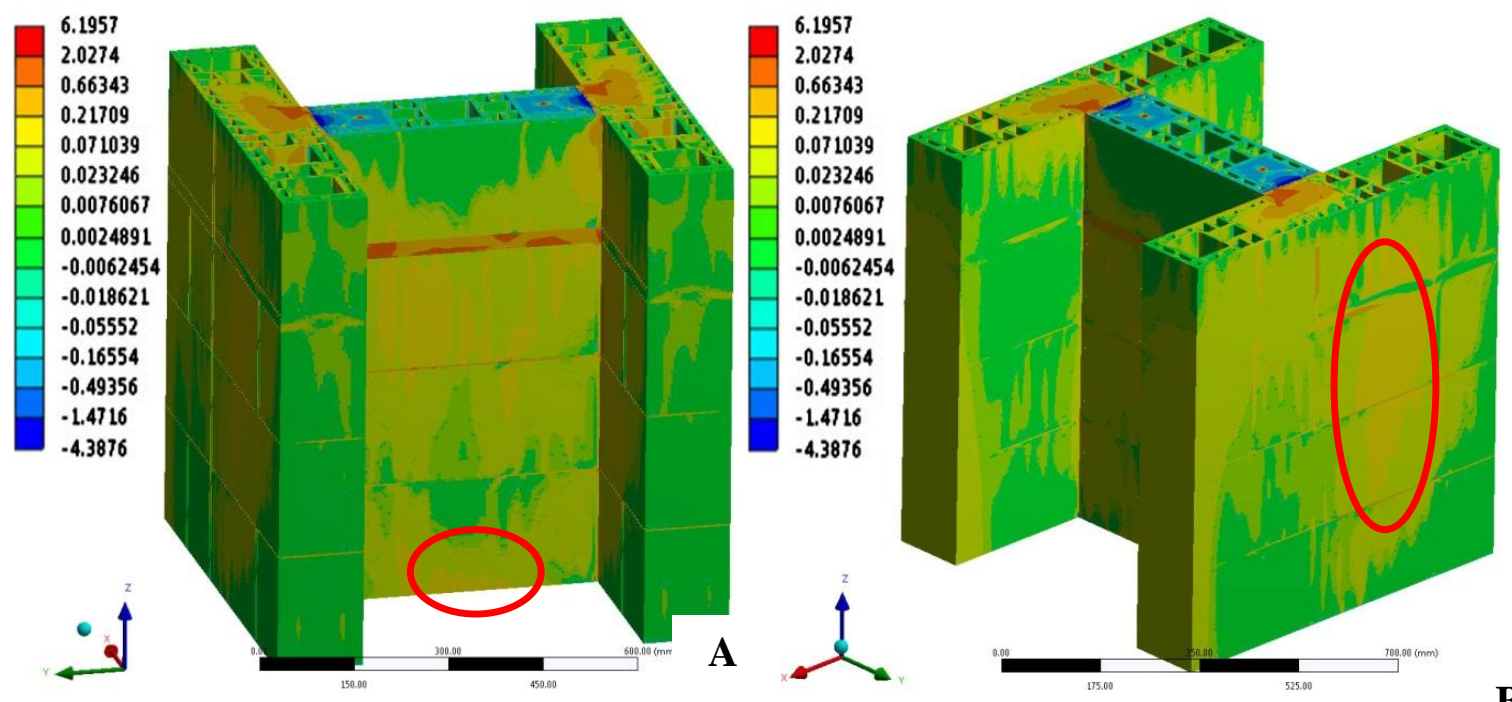

Figura 10 - Resultados referentes à tensão principal máxima do corpo de prova com seção transversal em " $\mathrm{H}$ " durante a aplicação de um carregamento de $60 \mathrm{kN}$

\section{Considerações finais}

Os resultados apresentados ao longo deste trabalho permitiram a obtenção das seguintes conclusões:

(a) em relação à argamassa, verificou-se que o uso de agregado miúdo muito fino, de alto teor de aglomerante, de baixo fator água/aglomerante e de dispersante orgânico, proporcionou à argamassa de assentamento/grauteamento um incremento expressivo de suas resistências à compressão e à tração na flexão. Porém, as altas resistências mecânicas da argamassa acabaram resultando na elevação significativa de seu módulo de elasticidade, ou seja, na grande redução de sua capacidade de acomodar as deformações; (b) em relação ao conjunto argamassa-unidade cerâmica, observou-se que a adoção de uma argamassa com resistências mecânicas elevadas proporcionou ao conjunto argamassa-unidade cerâmica um ganho ínfimo de resistência tanto à compressão quanto de aderência à tração na flexão e um comportamento extremamente frágil;

(c) em relação à armadura metálica, ressalta-se que sua presença tem influência no comportamento da conexão. Entretanto, a alteração do tipo de aço utilizado em sua confecção promove variações muito pequenas nos deslocamentos verticais e nas tensões normais verticais constatados; 
(d) em relação ao modelo adotado de conexão vertical, constatou-se que este promove uma ampliação significativa da área superficial de contato entre a argamassa e a unidade cerâmica, minimizando as influências negativas da alta capacidade de retenção de água e do baixo fator água/aglomerante da argamassa. Esse fato, aliado à resistência da argamassa à flexão e à compressão e ao uso de uma armadura metálica, induz à conexão um comportamento rígido, ou seja, ao aparecimento de forças de interação entre os painéis. Entretanto, os resultados obtidos tanto pelo método experimental quanto pela análise numérica demonstram que o comportamento da argamassa tem maior influência sobre o desempenho da conexão analisada que o da armadura metálica; e

(e) em relação à análise numérica, constatou-se que o desenvolvimento de um modelo numérico tridimensional que represente o objeto real (micromodelagem simplificada) em conjunto com as propriedades dos materiais e de uma malha altamente refinada composta de elementos estruturais SOLID186 e SOLID187 mostra-se capaz de apresentar resultados satisfatórios de deslocamentos verticais. O modelo gerado conseguiu obter valores próximos aos observados no ensaio experimental, apesar da complexidade do corpo de prova analisado. Os resultados demonstram que o emprego de uma argamassa com módulo de elasticidade e resistências mecânicas elevados na junção entre painéis contribuiu para minimizar a participação da armadura no desempenho do conjunto painéisconexões, de tal modo que a alteração no tipo de aço não influenciou seu comportamento. As propriedades da argamassa combinadas ao modelo de conexão adotado induziram a presença de interação entre os prismas, pois a forma como foi executada a ligação tornou possível que as tensões provenientes do carregamento vertical aplicado sobre o prisma central (painel central) também fossem distribuídas aos prismas da extremidade (painéis externos).

Desse modo, demonstra-se que o modelo avaliado de conexão vertical apresenta desempenho suficiente para contribuir com o comportamento dos painéis estruturais cerâmicos pré-fabricados, uma vez que os resultados mostram que esse modelo possui comportamento semelhante ao da amarração direta da alvenaria, ou seja, possibilita a homogeneização das tensões normais verticais entre os painéis adjacentes. Em outras palavras, permite considerar a existência da interação entre painéis, que resulta no aumento significativo da capacidade de carga destes. Esse fato o difere de alguns modelos de conexões usualmente empregados em sistemas pré-fabricados em alvenaria.

\section{Referências}

\author{
AMERICAN SOCIETY FOR TESTING AND \\ MATERIALS. ASTM E-518: standard test \\ method for flexural bond strength of masonry. \\ West Conshohocken, 2003a.
}
AMERICAN SOCIETY FOR TESTING AND MATERIALS. ASTM C-1314: standard test method for compressive strength of masonry units. Philadelphia, PA, 2003b.
ANSYS. [on-line]. Estados Unidos, 2011.
Disponível em:
<http://www.kxcad.net/ansys/ansys>. Acesso em: 5 jul. 2012.

ANTUNES, R. P. N. et al. Avaliação do Efeito da Reologia e da Energia de Impacto na Resistência de Aderência de Revestimentos de Argamassa. In: CONCRESSO PORTUGUÊS DE

ARGAMASSAS DE CONSTRUÇÃO, 3., Lisboa, Portugal, 2010. Anais... Lisboa, 2010.

\section{ASOCIACIÓN MERCOSUL DE} NORMALIZACIÓN. ABNT NM 26: agregado miúdo: amostragem. Rio de Janeiro, 2009a.

\section{ASOCIACIÓN MERCOSUL DE NORMALIZACIÓN. ABNT NM 27: agregado: redução da amostra de campo para ensaios de laboratório. Rio de Janeiro, 2001a.}

\section{ASOCIACIÓN MERCOSUL DE}

NORMALIZACIÓN. ABNT NM 46: agregado miúdo: determinação do material fino que passa através da peneira $75 \mu \mathrm{m}$, por lavagem. Rio de Janeiro, 2003a.

\section{ASOCIACIÓN MERCOSUL DE} NORMALIZACIÓN. ABNT NM 49: agregado miúdo: determinação de impurezas orgânicas. Rio de Janeiro, 2001b.

\section{ASOCIACIÓN MERCOSUL DE NORMALIZACIÓN. ABNT NM 52: agregado} miúdo: determinação da massa específica e massa aparente. Rio de Janeiro, 2009b.

ASOCIACIÓN MERCOSUL DE NORMALIZACIÓN. ABNT NM 248: agregados: determinação da composição granulométrica. Rio de Janeiro, 2003b.

\section{ASSOCIAÇÃO BRASILEIRA DE NORMAS}

TÉCNICAS. NBR 6467: agregados: determinação do inchamento de agregado miúdo: método de ensaio. Rio de Janeiro, 2006. 
ASSOCIAÇÃO BRASILEIRA DE NORMAS TÉCNICAS. NBR 7211: agregados para concreto: especificação. Rio de Janeiro, 2009.

ASSOCIAÇÃO BRASILEIRA DE NORMAS TÉCNICAS. NBR 7221: agregados: ensaio de qualidade de agregado miúdo. Rio de Janeiro, 1987.

ASSOCIAÇÃO BRASILEIRA DE NORMAS TÉCNICAS. NBR 7251: agregado em estado solto: determinação da massa unitária. Rio de Janeiro, 1982.

ASSOCIAÇÃO BRASILEIRA DE NORMAS TÉCNICAS. NBR 8215: prisma vazado de concreto simples para alvenaria estrutural: preparo e ensaio à compressão. Rio de Janeiro, 1983.

ASSOCIAÇÃO BRASILEIRA DE NORMAS TÉCNICAS. NBR 8522: concreto: determinação dos módulos estáticos de elasticidade e de deformação e da curva tensão-deformação. Rio de Janeiro, 2003.

ASSOCIAÇÃO BRASILEIRA DE NORMAS TÉCNICAS. NBR 12118: blocos vazados de concreto simples para alvenaria: determinação da absorção de água, do teor de umidade e da área líquida: método de ensaio. Rio de Janeiro, 2010.

ASSOCIAÇÃO BRASILEIRA DE NORMAS TÉCNICAS. NBR 13276: argamassa para assentamento e revestimento de paredes e tetos: preparo da mistura e determinação do índice de consistência. Rio de Janeiro, 2002.

ASSOCIAÇÃO BRASILEIRA DE NORMAS TÉCNICAS. NBR 13277: argamassa para assentamento e revestimento de paredes e tetos. Rio de Janeiro, 1995.

ASSOCIAÇÃO BRASILEIRA DE NORMAS TÉCNICAS. NBR 13278: argamassa para assentamento e revestimento de paredes e tetos: determinação da densidade de massa e do teor de ar incorporado. Rio de Janeiro, 2005a.

ASSOCIAÇÃO BRASILEIRA DE NORMAS TÉCNICAS. NBR 13279: argamassa para assentamento e revestimento de paredes e tetos: determinação da resistência à tração na flexão e à compressão. Rio de Janeiro, 2005b.

ASSOCIAÇÃO BRASILEIRA DE NORMAS TÉCNICAS. NBR 13281: argamassa para assentamento e revestimento de paredes e tetos: requisitos. Rio de Janeiro, 2001.

ASSOCIAÇÃO BRASILEIRA DE NORMAS TÉCNICAS. NBR 13600: solo: determinação do de matéria orgânica por queima a $440{ }^{\circ} \mathrm{C}$. Rio de Janeiro, 1999.
ASSOCIAÇÃO BRASILEIRA DE NORMAS

TÉCNICAS. NBR 15270-1: componentes cerâmicos: terminologia e Requisitos. Rio de Janeiro, 2005c.

ASSOCIAÇÃO BRASILEIRA DE NORMAS TÉCNICAS. NBR 15961-1: alvenaria estrutural: blocos de concreto. Parte 1: Projeto. Rio de Janeiro, 2011.

ASSOCIAÇÃO BRASILEIRA DE NORMAS TÉCNICAS. NBR NM ISO 3310-1: Peneiras de ensaio - Requisitos técnicos e verificação Parte 1: Peneiras de ensaio com tela de tecido metálico (ISO 3310-1, IDT). Rio de Janeiro, 2010.

CAMACHO, J. S. et al. An Experimental Study of Interaction Among Walls Scales Concrete Blocks. In: AUSTRALIAN MASONRY CONFERENCE, 6., Adelaide, 2001. Proceedings... Adelaide, 2001.

CAPUZZO NETO, V. Estudo Teórico e Experimental da Interação de Paredes de Alvenaria Estrutural Submetidas a Ações Verticais. 111 f. São Carlos, 2000. Dissertação (Mestrado em Engenharia Civil) - Escola de Engenharia de São Carlos, Universidade de São Paulo, São Carlos, 2000.

CAPUZZO NETO, V. Interação de Paredes em Alvenaria Estrutural Cerâmica Sob Ações Verticais. 2005. Tese (Doutorado em Engenharia Civil) - Escola de Engenharia de São Carlos, Universidade de São Paulo, São Carlos, 2005.

CORRÊA, M. R. S. Fluxo de Forças em Edifícios de Alvenaria Estrutural. 2003. Tese (Livredocência) - Escola de Engenharia de São Carlos, Universidade de São Paulo, São Carlos, 2003.

GERDAU. Aço Para Construção Civil.

Disponível em: <www.gerdau.com.br>. Acesso em: 5 jul. 2012.

GUIMARÃES CÉSAR, C. Desempenho Estrutural de Painéis Pré-Fabricados Com Blocos Cerâmicos. 2007. Tese (Doutorado em Engenharia Civil) - Programa de Pós-Graduação em Engenharia Civil, Universidade Federal de Santa Catarina, 2007.

LISSEL, S. L.; SHRIVE, N. G.; PAGE, A. Shear in Plain, Bed Joint Reinforced, and Posttensioned Masonry. Canadian Concrete Institute, v. 63, n. 11, nov. 2000.

PELETEIRO, S. C. Contribuições à Modelagem Numérica da Alvenaria Estrutural. $148 \mathrm{f}$. São Paulo, 2002. Tese (Doutorado em Engenharia) Escola de Engenharia de São Carlos, Universidade de São Paulo, São Paulo, 2002. 
SCHULTZ, A. E. et al. Seismic Resistance of Vertical Joints in Precast Shear Walls. In: CONGRESS OF FEDERATION INTERNATIONALE DE LA PRECONTRAINTE, 12., 1994. Proceedings... 1994.

SILVA, W. J. Estudo Experimental de Ligações Entre Paredes de Alvenaria Estrutural de Blocos Cerâmicos Sujeitas a Ações Verticais. Ilha Solteira, 2003. Dissertação (Mestrado em Engenharia Civil) - Faculdade de Engenharia, Universidade Estadual Paulista, Ilha Solteira, 2003.
SINHA, B. P.; HENDRY, A. W. Compressive Strength of Axially Load Brick Walls Stiffened Along Their Verticals Edges. In: INTERNATIONAL BRICK MASONRY

CONFERENCE, 5., Washington, 1979.

Proceedings... Washington, 1979. p. 254-261.

Revista Ambiente Construído

Associação Nacional de Tecnologia do Ambiente Construído

Av. Osvaldo Aranha, $99-3^{\circ}$ andar, Centro

Porto Alegre - RS - Brasil

CEP $90035-190$

Telefone: +55 (51) 3308-4084

Fax: +55 (51) 3308-4054

www.seer.ufrgs.br/ambienteconstruido

E-mail: ambienteconstruido@ufrgs.br

50 Manzano, R. de M.; Roman, H. R.; Gómez, L. A. 